Reprod. Nutr. Dévelop., 1986, 26 (1 B), 299-300.

\title{
Influence du niveau d'apport de soufre sur la synthèse d'acide ribonucléique et de protéines par les microorganismes du rumen en fermenteur semi-continu
}

Michelle DURAND, Geneviève HANNEQUART, Ph. BEAUMATIN, Christiane DUMAY, Françoise TASSERY

Station de Recherches de Nutrition, I.N.R.A. 78350 Jouy-en-Josas, France.

Summary. The effect of sulphur (S) on ribonucleic acid production and protein synthesis by rumen microbes has been studied with the Rumen Simulation Technique using a ureapurified substrate. A low $(8.4 \mathrm{mg} / \mathrm{l})$ and a high $(31 \mathrm{mg} / \mathrm{l})$ level of $S$ in the infused buffer were compared. The low $\mathrm{S}$ level induced about $30 \%$ less protein $\mathrm{N}$ and microbial $\mathrm{N}$ and decreased the efficiency of protein synthesis.

Le soufre (S) est nécessaire à la digestion et à la synthèse de protéines microbiennes dans le rumen, mais l'apport optimal n'a pas encore été quantifié avec exactitude (Durand, 1984). L'emploi d'un fermenteur semi-continu simulant le rumen (“ Rusitec, ») (Czerkawski et Breckenridge, 1977) devrait permettre de déterminer les besoins en $\mathrm{S}$ de la microflore selon le type d'aliment utilisé, dans la mesure où une estimation précise de la protéosynthèse microbienne pourrait être effectuée. Dans ce but, nous avons utilisé l'acide ribonucléique (ARN) comme marqueur de la protéosynthèse microbienne (McAllan et Smith, 1983), avec comme substrat un aliment purifié contenant de l'urée comme seule source d'azote, et ce, en présence de deux niveaux d'apport de soufre.

Matériel et méthodes. Du liquide et du contenu solide de rumen provenant de 3 agneaux âgés de 7 mois, préalablement adaptés au régime purifié sans protéines, sont inoculés dans les quatre fermenteurs (1 I de capacité). L'aliment purifié (amidon de maïs 40,2 ; cellulose 28,3 ; cérélose 24,0 ; urée 4,4 ; huile de maïs $3,0)$ est introduit dans des sachets en nylon $(160 \times 80 \mathrm{~mm}$, voie de maille de $150 \mu \mathrm{m}$ à raison de $15,6 \mathrm{~g}$ de matière sèche (MS) par sac. Les minéraux, y compris le soufre, sont apportés par la perfusion des mélanges tampons (environ $1 \mathrm{l} / 24 \mathrm{~h} /$ fermenteur). Deux fermenteurs reçoivent le tampon " pauvre » en soufre, soit $8,4 \mathrm{mg} \mathrm{S} / \mathrm{l}$ provenant des sulfates du mélange d'oligo-éléments, et les deux autres fermenteurs le tampon "riche " supplémenté par $100 \mathrm{mg}$ de $\mathrm{Na}_{2} \mathrm{SO}_{4} / \mathrm{l}$, soit au total $31,0 \mathrm{mg} \mathrm{S} / \mathrm{l}$. Après une période d'adaptation de 6 jours, on détermine pour chacun des fermenteurs, sur 5 effluents de $24 \mathrm{~h}: \mathrm{N}$-protéique précipité au TCA (10\% concentration finale), $\mathrm{N}-\mathrm{NH}_{3}, \mathrm{~N}$-urée et les acides gras volatils (AGV). Les quantités de matière sèche et de cellulose (Van Soest) disparues sont mesurées sur les sachets correspondants. Les teneurs en ARN et en azote (NT) du culot microbien obtenu par centrifugation fractionnée du mélange 
du contenu du sachet et de l'effluent sont déterminées sur une période de $24 \mathrm{~h}$ en triple sur le mélange des contenus correspondant à chaque traitement. L'ARN est déterminé pour chaque fermenteur sur trois effluents de $24 \mathrm{~h}$, et sur les résidus des sachets de $48 \mathrm{~h}$ (1 prélèvement). L'azote microbien est calculé d'après : NT/N-ARN bact. $\times \mathrm{N}-\mathrm{ARN}$ effluent ou sachet.

Résultats et discussion. Les productions d'azote protéique et d'ARN dans les effluents avec le tampon pauvre en soufre sont significativement plus faibles qu'avec le tampon riche. Les valeurs de l'azote microbien par la méthode ARN sont voisines de celles de l'azote protéique mesuré pendant les mêmes périodes (tabl. 1). Pour l'ensemble des valeurs $(n=10)$ le coefficient de corrélation est de 0,93 .

TABL. 1. - Influence du soufre sur la protéosynthèse et la fermentation.

\begin{tabular}{|c|c|c|}
\hline & Tampon pauvre & Tampon riche \\
\hline 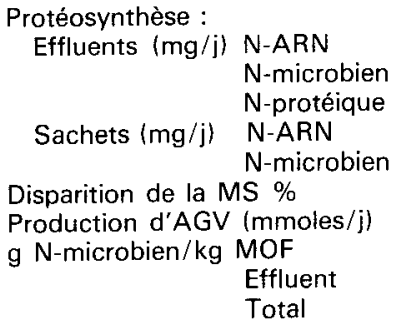 & $\begin{array}{c}13,8 \pm 0,8 \\
104 \quad \pm 6 \\
108 \pm 5 \\
2,68 \\
20,2 \\
76,6 \pm 1,3 \\
93,8 \pm 3,5 \\
12,5 \\
18,5\end{array}$ & $\begin{array}{c}18,1 \pm 1,0 \\
167 \pm 9 \\
152 \pm 10 \\
2,14 \\
19,8 \\
79,6 \pm 3,0 \\
94,8 \pm 2,7 \\
14,8 \\
20,7\end{array}$ \\
\hline
\end{tabular}

L'azote microbien associé aux résidus des sachets ne diffère pas selon les traitements. En tenant compte de l'azote microbien total (sachet + effluent) obtenu avec le tampon pauvre en soufre, la valeur du rapport $\mathrm{N}$ utilisé/S disponible s'élève à 14,8 , ce qui correspond à la valeur moyenne du rapport $N / S$ des microorganismes (Durand, 1984). L'apport du S par perfusion continue aurait permis une utilisation totale de cet élément lorsque sa quantité était limitante.

La carence en soufre, par contre, ne limite de façon significative ni la disparition de la MS, ni la production d'AGV (tabl. 1). Aussi le rendement de la protéosynthèse microbienne calculé en estimant la matière organique fermentée (MOF) d'après les AGV produits(moles) : g MOF $=\left[1 / 2\left(C_{2}+C_{3}\right)+C_{4}+C_{5}\right] \times 162$ a été notablement abaissé par la carence en soufre quel que soit l'azote microbien considéré (effluents ou sachets + effluents) (tabl. 1), ce qui confirme qu'une carence en soufre est susceptible d'entraîner un découplage des fermentations (Durand, 1984).

En conclusion ces résultats soulignent l'importance du soufre dans la digestion microbienne lorsque l'aliment est purifié ; ils devront être vérifiés avec des aliments naturels.

Czerkawski J. W., Breckenridge G., 1977. Design and development of a long term rumen simulation technic (Rusitec). Br. J. Nutr., 38, 371-384.

Durand M., 1984. Le rôle du soufre dans le rumen, conséquences pour les besoins et recommandations d'apport chez le ruminant $\mathrm{M} 1-\mathrm{M} 31$. In Le point sur le magnésium et le soufre en alimentation animale, éd. CAAA, INA-PG, Paris.

McAllan A. B., Smith R. H., 1983 . Estimation of flows of organic matter and nitrogen components in postruminal digesta and effects of level of dietary intake and physical form of protein supplement on such estimates. Br. J. Nutr., 49, 119-127. 